\title{
Valproic acid selectively reduces the low-threshold (T) calcium current in rat nodose neurons
}

\author{
Kevin M. Kelly ${ }^{1}$, Robert A. Gross ${ }^{1}$ and Robert L. Macdonald ${ }^{1,2}$ \\ Departments of ${ }^{\prime}$ Neurology and ${ }^{2}$ Physiology, University of Michigan Medical Center, Ann Arbor. \\ MI, 48104 (U.S.A.)
}

(Received 23 February 1990; Revised version received 19 April 1990; Accepted 20 April 1990)

Key words: Valproic acid; Calcium current; Whole cell patch clamp; Antiepileptic drug

\begin{abstract}
Valproic acid (VPA) is an antiepileptic drug used in the treatment of a wide variety of human seizures including generalized absence (GA) (petit mal) seizures. The mechanism of action of VPA in controlling GA seizures is not known. We tested the effects of VPA on the $\mathrm{Ca}^{2+}$ current components of acutely dissociated rat nodose ganglion neurons. VPA reduced the low-threshold $(\mathrm{T}) \mathrm{Ca}^{2+}$ current at clinically relevant concentrations but had no effect on the high-threshold ( $\mathrm{N}$ and $\mathrm{L}$ ) current components. The effect on $\mathrm{T}$ current was concentration-dependent and most apparent at peak current. There was little effect seen on late current. VPA did not affect the rate or voltage-dependency of $T$ current activation. The selective reduction of $\mathrm{T}$ current may be a means by which VPA is effective in controlling GA seizures.
\end{abstract}

Valproic acid (VPA) is an antiepileptic drug used in the treatment of a wide spectrum of human seizure types including generalized tonic-clonic, generalized absence (GA), myoclonic, secondary generalized tonic-clonic and simple and complex partial seizures with or without secondary generalization. Despite VPA's broad clinical use and therapeutic efficacy, its mechanism of action in controlling seizures is not understood completely. Hypotheses include augmenting $\gamma$-aminobutyric acid (GABA)mediated inhibition by enhancing presynaptic release of GABA $[3,18,22]$ and useand voltage-dependent limitation of high-frequency repetitive firing of $\mathrm{Na}^{+}$-dependent action potentials [20]. Neither of these hypotheses adequately explains all of VPA's antiepileptic activity and, specifically, its activity against GA seizures.

Ethosuximide and dimethadione, drugs effective in the control of GA seizures, have recently been shown to reduce $\mathrm{Ca}^{2+}$ currents in thalamic and sensory neurons $[4,8]$. The $\mathrm{Ca}^{2+}$ current components recorded in these tissues include a transient lowthreshold current $(T)$, a transient high-threshold current $(N)$, and a slowly inactivat-

Correspondence: R.L. Macdonald, Neuroscience Laboratory Building, 1103 E. Huron St., Ann Arbor, MI 48104, U.S.A. 
ing high-threshold current (L). Studies in thalamic neurons [4, 15] and inferior olivary neurons $[16,17]$ suggest that $T$ currents are responsible for the low-threshold $\mathrm{Ca}^{2+}$ spike that underlies oscillatory bursting in these cells. The low-threshold $\mathrm{Ca}^{2+}$ spike may also be involved in the generation of thalamocortical rhythms, such as sleep spindles, and possibly, the abnormal electroencephalographic $3 \mathrm{~Hz}$ spike-andwave rhythm seen in human GA seizures. Since ethosuximide, dimethadione and VPA are all capable of blocking pentylenetetrazol-induced seizures in animals [14] and are effective in treating GA seizures, these drugs may have a common mechanism of action. Ethosuximide and dimethadione selectively reduced the T current in thalamic neurons [4], although VPA did not have this effect. However, studies in area CA1 of rat hippocampus suggest that VPA may act by increasing $\mathrm{K}^{+}$currents and/or reducing $\mathrm{Ca}^{2+}$ currents $[2,7,21]$.

We chose therefore to examine the effect of VPA on the $\mathrm{Ca}^{2+}$ current components of acutely dissociated rat nodose ganglion neurons. Nodose neurons were easy to prepare and were similar to dorsal root ganglion neurons with regard to $\mathrm{Ca}^{2+}$ current components [6,9] and antiepileptic drug effects [8]. Most importantly, nodose neurons had $\mathrm{Ca}^{2+}$ current components $[10,11]$ similar to neurons in rat thalamus $[5$, 23], hypothalamus [1] and dorsal horn [12]. These latter considerations suggested that antiepileptic drug effects on nodose neurons could be similar to effects on central neurons involved in seizure activity. Our results show that VPA produced a reversible reduction of $T$ current in nodose neurons.

We determined the effects of VPA using the whole cell variation of the patch clamp technique. Acutely dissociated neurons were obtained from nodose ganglia of 6-10 day old rats according to the method described by Ikeda et al. [13], as modified by Gross et al. [11]. Briefly, the ganglia were removed, placed in oxygenated $\mathrm{Ca}^{2+}$ - and $\mathrm{Mg}^{2+}$-free buffer and collagenase $(1 \mathrm{mg} / \mathrm{ml})$ was added. Following addition of enzyme inhibitor ( $5 \%$ fetal calf serum), the cells were triturated, centrifuged, resuspended, plated and incubated at $37^{\circ} \mathrm{C}$ in a $93 \%$ air $/ 7 \% \mathrm{CO}_{2}$ atmosphere. Recordings were made using glass micropipettes (1.5-3.0 M 2 ) filled with a solution of (in $\mathrm{mM}$ ): $\mathrm{CsCl} 140, \mathrm{CsOH} 30, \mathrm{HEPES} 10$, EGTA 10, ATP 5 and GTP $0.1(\mathrm{pH} 7.2-7.3, \sim 300$ mOsm). Cells were bathed in a solution of (in $\mathrm{mM}$ ): choline $\mathrm{Cl} 67$, TEA 100, glucose 5.6, $\mathrm{KCl} 5.3, \mathrm{CaCl}_{2} 5.0, \mathrm{MgCl}_{2}$ 0.8, HEPES 10 ( $\mathrm{pH} \mathrm{7.35,} 320$ mOsm). Cesium and TEA were used to block $\mathrm{K}^{+}$currents; choline was used to block $\mathrm{Na}^{+}$currents. Following sealing of the electrode to the cell and rupture of the membrane patch, the cell was hyperpolarized to a holding potential $\left(V_{\mathrm{h}}\right)=-90 \mathrm{mV}$ to fully remove steadystate inactivation of $T$ currents. The program pCLAMP (Axon Instruments) was used to generate voltage step commands and to digitize $(5.6 \mathrm{kHz})$ and store current traces. All experiments were conducted at room temperature.

T currents were evoked at clamp potentials $\left(V_{\mathrm{c}}\right)$ at or positive to $-55 \mathrm{mV}$. Typically, $T$ currents were evoked by using voltage steps of $100 \mathrm{~ms}$ duration delivered every $5 \mathrm{~s}$ in $5 \mathrm{mV}$ increments ranging from a $V_{\mathrm{c}}$ of -65 to $-20 \mathrm{mV}$. Three measurements of $T$ current magnitude were made: the peak inward current, the current at $100 \mathrm{~ms}$ and the area under the current curves (total current). Maximal T current was defined as the largest evoked peak $\mathrm{T}$ current evoked at a $V_{\mathrm{c}}$ (usually $-35 \mathrm{mV}$ ) nega- 
tive to that at which more slowly inactivating current components ( $\mathrm{N}$ and $\mathrm{L}$ ) were evoked. This resulted in slight underestimation of $\mathrm{T}$ current magnitude but allowed for examination of those currents with little high-threshold current contamination. $T$ currents were stable and showed little change in amplitude over the course of an experiment. $T$ current magnitudes varied among neurons from barely detectable to greater than $1 \mathrm{nA}$. Many neurons had maximal T currents less than $200 \mathrm{pA}$ that were difficult to analyze quantitatively and thus were assessed only for a possible VPA effect. For VPA-responsive neurons, the potential effect of VPA on T current activation and inactivation rates was assessed by normalizing VPA-reduced currents to control peak $\mathrm{T}$ currents and superimposing the current traces for comparison. Currents containing $\mathrm{N}$ and $\mathrm{L}$ components were evoked from a $V_{\mathrm{h}}$ at or negative to -80 $\mathrm{mV}$ at a $V_{\mathrm{c}}$ at or positive to $-20 \mathrm{mV}$. These currents were evoked every $60 \mathrm{~s}$ and, in contrast to $T$ currents, declined $30-50 \%$ during a 20 min recording. All currents were leak subtracted for analysis.
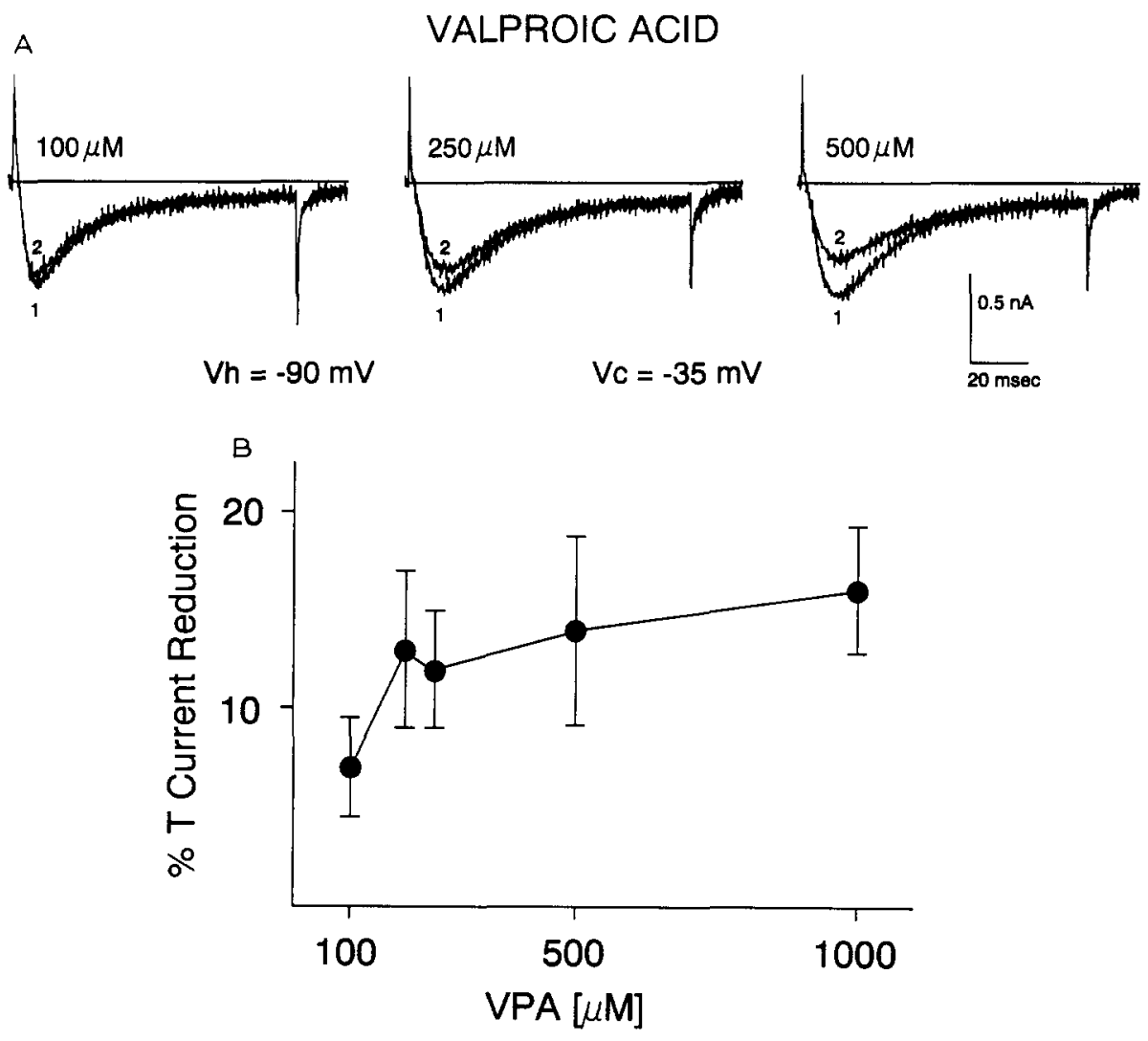

Fig. 1. VPA reduced the $T$ current component in rat nodose ganglion neurons. A: T currents were evoked from a $V_{\mathrm{h}}=-90 \mathrm{mV}$ at a $V_{\mathrm{c}}=-35 \mathrm{mV}$ in the absence (trace 1) and presence of VPA $(100 \mu \mathrm{M}, 250 \mu \mathrm{M}$ and $500 \mu \mathrm{M}$; trace 2). Recovery trials (not shown) were identical to control trials. B. Concentrationresponse curve for 14 VPA-responsive neurons tested with single or multiple concentrations of VPA. 
VPA (100-1000 $\mu \mathrm{M})$ was prepared daily by dissolving its sodium salt in external solution used as diluent. VPA was tested initially at $1 \mathrm{mM}$ to screen for drug effect and then tested within the range of antiepileptic levels of free VPA for adult humans $(17.5-210 \mu \mathrm{M})$ [19]. The drug was applied by pressure ejection (1 psi) from a blunttipped micropipette positioned $50 \mu \mathrm{m}$ from the cell soma before and during voltage step commands. Currents were evoked during delivery of the drug in order to attain a constant drug concentration at the soma. Micropipettes containing different concentrations of drug were substituted sequentially with control and recovery trials and were removed from the bath solution when not in use. Application of diluent alone had no effect on evoked currents.

VPA reduced T currents in 35/39 neurons of which 14 were suitable for quantitative analysis. Fig. 1A shows the effect of VPA on T currents at concentrations of 100
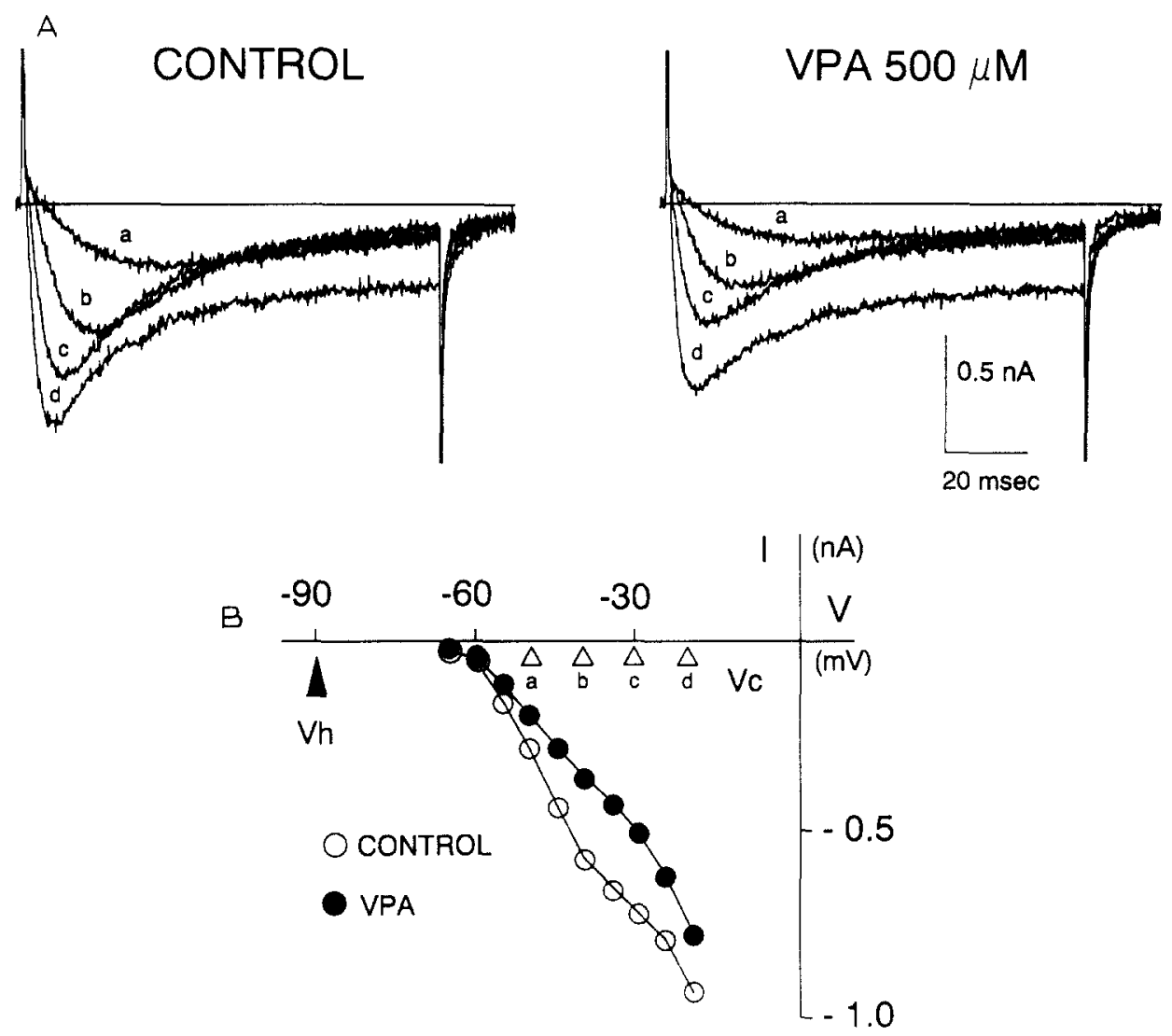

Fig. 2. VPA reduced the $T$ current without affecting the voltage dependency of the current-voltage relation. A: T currents were evoked from a $V_{\mathrm{h}}=-90 \mathrm{mV}$ at a $V_{\mathrm{c}}$ ranging from -65 to $-20 \mathrm{mV}$. Representative traces show currents evoked at a $V_{\mathrm{c}}$ of -50 to $-20 \mathrm{mV}$ (a d, respectively). Currents evoked at a $V_{\mathrm{c}}=-20 \mathrm{mV}$ (d) showed slower inactivation than those evoked at more negative $V_{\mathrm{c}}$, indicating co-activation of high-threshold $\mathrm{Ca}^{2+}$ current components. B: peak $\mathrm{Ca}^{2+}$ current-voltage relation plots derived from currents recorded from the same neuron shown in $\mathrm{A}$. The percent reduction of peak current was relatively constant over the $T$ current activation range. 
$500 \mu \mathrm{M}$ in a single neuron. VPA reduced peak T current by $9 \%(100 \mu \mathrm{M}), 14 \%(250$ $\mu \mathrm{M})$ and $34 \%(500 \mu \mathrm{M})$, an effect that was fully reversible within several seconds. Total T current reduction was similar: $10 \%(100 \mu \mathrm{M}), 19 \%(250 \mu \mathrm{M})$ and $27 \%(500$ $\mu \mathrm{M}$ ) (data not shown). VPA reduced T current in a concentration-dependent manner in all cells tested, but in most cases, the effect was more modest. For example, in 14 VPA-responsive cells, tested with either single or multiple concentrations of VPA, T current reduction was $7 \%$ at $100 \mu \mathrm{M}, 13 \%$ at $200 \mu \mathrm{M}$ and $16 \%$ at $1000 \mu \mathrm{M}$ (Fig. 1B).

To determine if the effect of VPA was voltage-dependent, we tested the effect of VPA at several $V_{\mathrm{c}}$ (Fig. 2A). Currents were evoked at a $V_{\mathrm{c}}$ ranging from -65 to -20 $\mathrm{mV}$ from a $V_{\mathrm{h}}=-90 \mathrm{mV}$. VPA reduced $\mathrm{T}$ current amplitude at a $V_{\mathrm{c}}$ at or positive to $-55 \mathrm{mV}$. Fig. $2 \mathrm{~B}$ shows the current-voltage relation of this cell over the activation range for T current. There was no effect of VPA on voltage-dependency and the percent reduction of T current by VPA was relatively constant throughout the activation range (29-36\%). T currents appeared to have activation kinetics governed by a single time constant whereas current inactivation appeared to have an early phase $(\sim 30$ $\mathrm{ms}$ following peak) and a late phase (beyond $\sim 30 \mathrm{~ms}$ following peak), suggesting more than one time constant for inactivation. VPA-reduced currents normalized to control peak $T$ currents showed no significant difference in activation rate or the early phase of inactivation. However, the late phase of inactivation showed little VPA effect. This raises the possibility that $T$ current may have a VPA non-responsive inactivating phase or that the late phase of inactivation may be due to high-threshold current components on which VPA showed little or no effect (data not shown).

The main finding of this study is that VPA reduced whole cell voltage-dependent $T$ currents in nodose neurons when tested at concentrations within the therapeutic range of antiepileptic free plasma levels in man. The reduction of $T$ current was small in most of the cells tested and less than that shown for ethosuximide and dimethadione in thalamic relay neurons [4]. However, it is possible that small reductions of this current in central neurons could prevent the occurrence of the low-threshold $\mathrm{Ca}^{2+}$ spike, and thereby, be significant in the control of phasic electrical discharges seen in some types of seizures. VPA showed no effect on the voltage-dependency of $T$ current activation, or on the rates of activation or inactivation. These results were similar to those found in thalamic neurons for ethosuximide and dimethadione [4]. These findings suggest that the mechanism of action of these drugs on $T$ currents may be similar and that $T$ current reduction may be one of multiple mechanisms of action of VPA in central neurons. For example, VPA, phenytoin, and carbamazepine are all effective in controlling certain partial and generalized seizures, presumably by use- and voltage-dependent limitation of high frequency repetitive firing of action potentials [20]. However, phenytoin and carbamazepine are ineffective against GA seizures and do not reduce $T$ currents in thalamic neurons at clinically relevant concentrations [4]. This suggests that if $T$ currents are involved in the expression of GA seizures, reduction of these currents may underlie the effectiveness of VPA against this seizure type.

We thank Ms. Nancy Fox Ciliax and Mr. Sean C. Hanson for preparation of the cell cultures, Dr. Carl J. Rogers for computer hardware and software implementation 
and Mr. David M. Rock for assistance with calculations. Supported in part by NIH NINCDS 1 T32 NS07222 and an American Academy of Neurology Research Fellowship Award to K.M.K., NS 01019 and NS 19613 to R.A.G. and DA04122 to R.L.M.

1 Akaike, N., Kostyuk, P.G. and Osipchuk, Y.V., Dihydropyridine-sensitive low-threshold calcium channels in isolated rat hypothalamic neurones, J. Physiol., 412 (1989) 181-195.

2 Agopyan, N., Avoli, M., Rieb, L. and Tancredi, V., Depression of hippocampal low calcium field burst by the antiepileptic drug valproic acid. Neurosci. Lett., 60 (1985) 5762.

3 Chapman, A., Keane, P.E., Meldrum, B.S., Simiand, J. and Vernieres, J.C., Mechanism of anticonvulsant action of valproate, Prog. Neurobiol., 19 (1982) 315-399.

4 Coulter. D.A., Huguenard. J.R. and Prince, D.A., Characterization of ethosuximide reduction of lowthreshold calcium current in thalamic neurons, Ann. Neurol., 25 (I989) 582-599.

5 Coulter, D.A., Huguenard, J.R. and Prince, D.A., Calcium currents in rat thalamocortical relay neurones: kinetic properties of the transient, low-threshold current, J. Physiol., 414 (1989) $587-604$.

6 Fox, A.F., Nowycky, M.C. and Tsien, R.W., Kinetic and pharmacological properties distinguishing three types of calcium currents in chick sensory neurones. J. Physiol., 394 (1987) 149-172.

7 Franceschetti, S., Hamon, B. and Heinemann, U., The action of valproate on spontaneous epileptiForm activity in the absence of synaptic transmission and on evoked changes in $\left[\mathrm{Ca}^{2+}\right]_{0}$ and $\left[\mathrm{K}^{+}\right]_{0}$ in the hippocampal slice, Brain Res., 386 (1986) 111

8 Gross, R.A., Kelly, K.M. and Macdonald, R.L., Ethosuximide and dimethadione selectively reduce calcium currents in cultured sensory neurons by different mechanisms, Neurology, 39 Suppl. 1 (1989) 412.

9 Gross, R.A. and Macdonald, R.L.. Differential actions of pentobarbitone on calcium current components of mouse sensory neurones in culture, J. Physiol., 405 (1988) 187203.

10 Gross, R.A.. Macdonald, R.L. and Uhler, M.D., The cyclic AMP-dependent protein kinase catalytic subunit selectively enhances calcium currents in rat nodose neurones, J. Physiol., in press.

11 Gross, R.A., Wiley, J.W., Ryan-Jastrow, T. and Macdonald, R.L., Regulation by GTP and its stable thiol derivatives of calcium current components in rat nodose ganglion neurons, J. Mol. Pharmacol., 37 (1990) $546-553$.

12 Huang, L.-Y.M.. Calcium channels in isolated rat dorsal horn neurones, including labelled spinothalamic and trigeminothalamic cells, J. Physiol, 411 (1989) $161 \cdots 177$.

13 Ikeda, S.R., Schofield, G.G. and Weight. F.F.. Na ${ }^{+}$and $\mathrm{Ca}^{2+}$ currents of acutely isolated adult rat nodose ganglion cells, J. Neurophysiol., 55 (1986) 527-539.

14 Krall, R.L.. Penry, J.K., White, B.G., Kupferberg, H.J. and Swinyard, E.A.. Antiepileptic drug development. II. Anticonvulsant drug screening. Epilepsia, 19 (1978) $409-428$.

15 Llinas, R. and Jahnsen, H., Electrophysiology of mammalian thalamic neurones in vitro, Nature, 297 (1982) 406408 .

16 Llinas, R. and Yarom, Y., Electrophysiology of mammalian inferior olivary neurones in vitro. Different types of voltage-dependent ionic conductances, J. Physiol., 315 (1981) 549 - 567.

17 Llinas, R. and Yarom. Y., Properties and distribution of ionic conductances generating electroresponsiveness of mammalian inferior olivary neurones in vitro, J. Physiol. 315 (1981) 569-584.

18 Loscher, W., Valproate induced changes in GABA metabolism at the subcellular level, Biochem. Pharmacol., 30 (1981) 1364-1366.

19 Macdonald, R.L. and McLean. M.J., Anticonvulsant drugs: mechanisms of action, Adv. Neurol., 44 (1986) 713.736 .

20 McLean, M.J. and Macdonald, R.L., Sodium valproate, but not ethosuximide, produces use- and voltage-dependent limitation of high frequency repetitive firing of action potentials of mouse central neurons in cell culture, J. Pharmacol. Exp. Ther., 237 (1986) 1001-1011.

21 Rose, G.M., Olpe, H.R. and Haas, H.L., Testing of prototype antiepileptics in hippocampal slices, N.S. Arch. Pharmacol., 13 (1986) 425455

22 Sawaya, M.C.B., Horton, R.W. and Meldrum, B.S., Effects of anticonvulsant drugs on the cerebra! enzymes metabolizing GABA, Epilepsia, 16 (1975) 649655

23 Suzuki, S. and Rogawski, M.A., T-type calcium channels mediate the transition between tonic and phasic firing in thalamic neurons. Proc. Natl. Acad. Sci. U.S.A., 86 (1989) 72287232. 